\title{
Anomalous mediastinal left lower lobe anterior segmental artery (A8) accidentally divided during left VATS upper lobectomy: a case report
}

\section{Thirugnanam Agasthian}

Division of Surgical Oncology, National University Cancer Institute (NCIS), Singapore, Singapore

Correspondence to: Thirugnanam Agasthian, MBBS, MMed (Surgery), FRCS (Ed), FRCS (G). Division of Surgical Oncology, National University Cancer Institute (NCIS), \#14-12 Mt. Elizabeth Medical Centre, 3 Mt. Elizabeth, Singapore 228510, Singapore. Email: t.agasthian@gmail.com.

\begin{abstract}
Bronchovascular anatomical variations can pose technical challenges during lobectomy and especially segmentectomy where these structures are embedded deep in the lung parenchyma. Familiarity with these anatomical variations helps avoid intraoperative injury and accidental division. Mediastinal origin of left upper lobe apicoposterior (truncus superior) and lingula arterial branches (A4+5) is common. However mediastinal origin of left lower lobe segmental pulmonary branches is very rare and has not been reported in the literature. An anomalous mediastinal origin of left lower lobe anterior segmental artery (A8) noted during a left video-assisted thoracic surgery (VATS) upper lobectomy in a 69 years old male with stage 1 lung cancer is described. The artery was mistaken for a mediastinal lingula branch (A4+5) during surgery and was divided accidentally. The injury was recognised intraoperatively and primary end to end vascular repair was done by VATS, with the patient making an uneventful recovery. Awareness of this rare anatomical variant can help prevent intraoperative vascular injury or accidental ligation during left VATS lobectomy. Injuries due to anomalous bronchovascular anatomical variations can be prevented by preoperative planning by 3-dimensional contrast enhanced computer tomography and by careful intraoperative dissection and identification of mediastinal and interlobar vessels distally into the respective segments before ligation.
\end{abstract}

Keywords: Lung; anomalous anatomy; video-assisted thoracic surgery (VATS); case report

Received: 15 June 2020; Accepted: 07 December 2020; Published: 20 January 2023.

doi: 10.21037 /jovs-20-139

View this article at: http://dx.doi.org/10.21037/jovs-20-139

\section{Introduction}

Bronchovascular anatomical variations can pose technical challenges during lobectomy and segmentectomy (1). Familiarity with these anatomical variations and careful identification during surgery can prevent accidental intraoperative injury or division. Pulmonary arterial vessel originating from the mediastinal aspect of the left main pulmonary artery is termed mediastinal type. Vessels arising distal to the truncus superior from the truncus intermedius in the fissure is the interlobar type. Vessels originating within the intralobar lung segment is the segmental or subsegmental types. Truncus superior have a mediastinal origin from the left main pulmonary artery and are the commonest mediastinal types (2). The lingular arterial supply may have a mediastinal origin where it is solely mediastinal in $18 \%$ and mixed mediastinal and interlobar in $12 \%$. The segmental arterial supply (A8) is solely intralobar and mediastinal origin has not been reported previously. In this case report a rare anomalous mediastinal origin of a left lower lobe anterior segmental artery (A8) accidently divided during a left video-assisted thoracic surgery (VATS) upper lobectomy is described.

I present the following article in accordance with the CARE reporting checklist (available at https://jovs. amegroups.com/article/view/10.21037/jovs-20-139/rc). 


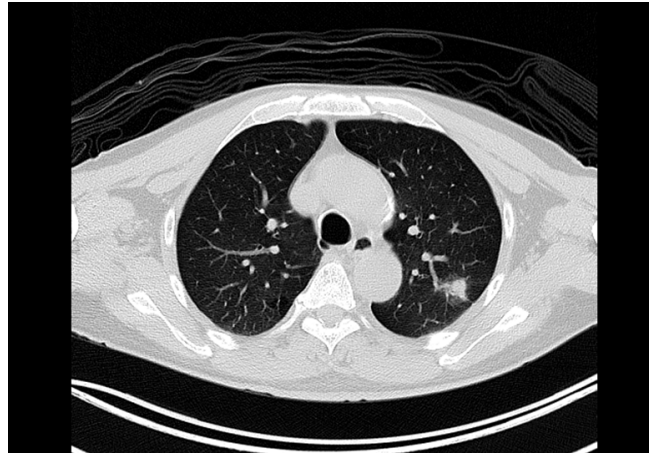

Figure 1 CT scan thorax showing left upper lobe lung cancer.

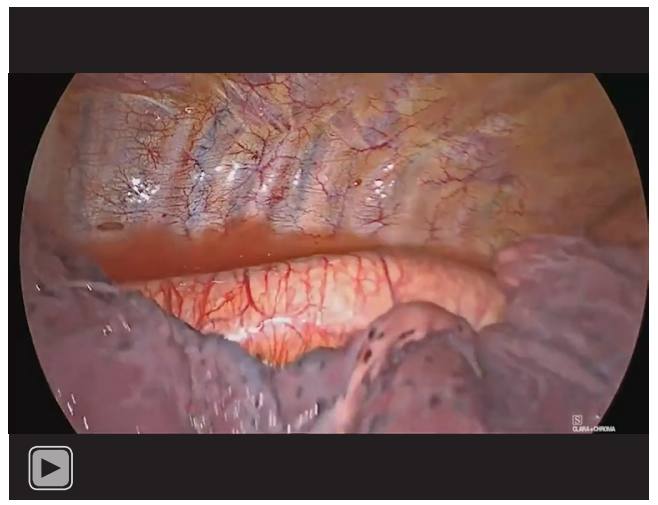

Video 1 Left video assisted thoracoscopic lobectomy upper lobectomy.

\section{Case presentation}

Patient is a 69 years old male non-smoker with a past history of carcinoma of prostate. During routine positron emission tomography (PET) computed tomography (CT) surveillance scan for prostate cancer a solitary left upper lobe spiculated nodule suspicious for lung cancer was detected (Figure 1). He underwent a left VATS wedge excision of the nodule. Intraoperative frozen section analysis of the nodule confirmed it to be a non-small cell lung cancer. A completion left VATS upper lobectomy and systematic lymph node dissection was done at the same session. During the lobectomy the interlobar lingula A4 and A5 vessels were noted to be small. After division of the upper lobe truncus and interlobar arterial branches a mediastinal origin of a segmental artery was noted. Due to the mediastinal origin and the small interlobar A4+5 lingula branches it was deemed to be a mediastinal lingula artery and was stapled and divided. However during mobilisation

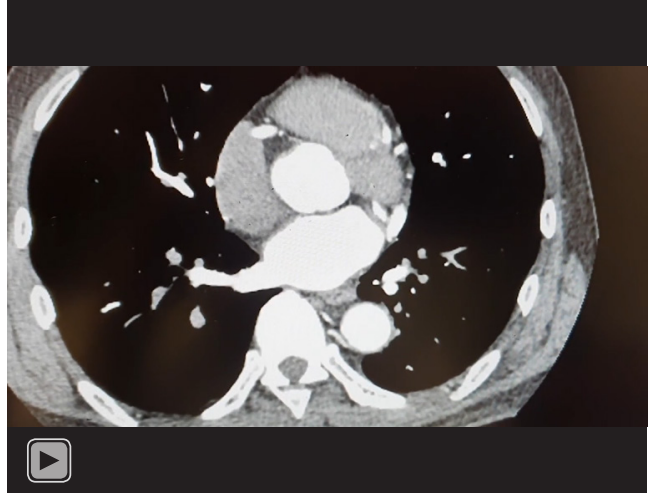

Video 2 CT coronary showing anomalous mediastinal A8.

of the left upper lobe bronchus it was noted that the divided mediastinal artery was actually supplying the anterior (S8) segment of lower lobe and not the lingula segment. The lobectomy was completed by dividing the upper lobe bronchus and major fissure with staplers. Primary anastomosis of the divided A8 vessels was then reconstructed by VATS. The proximal and distal ends were mobilised to ensure a tension free anastomosis. Proximal and distal control of the pulmonary vessels was obtained with vascular clamps. The proximal and distal stapled ends were divided and primary end to end anastomosis was done with two continuous 6-0 prolene sutures, starting first with the posterior vascular wall and then finishing with the anterior wall. After completion of the anastomosis the clamps were removed and the anastomosis was checked for patency and hemostasis. Air leak check was done followed by application of tissue glue (Video 1). Patient made an uneventful recovery and was discharged on post-operative day 2. Final histology was adenocarcinoma stage 1a (T1N0M0). A retrospective review of a CT coronary scan done 6 years previously did demonstrate the presence of this anomalous vessel (Video 2).

All procedures performed in this study were in accordance with the ethical standards of the institutional and/or national research committee(s) and with the Helsinki Declaration (as revised in 2013). Written informed consent was obtained from the patient for publication of this case report and accompanying images and videos. A copy of the written consent is available for review by the editorial office of this journal.

\section{Discussion}

Bronchovascular anatomical variations can pose technical 


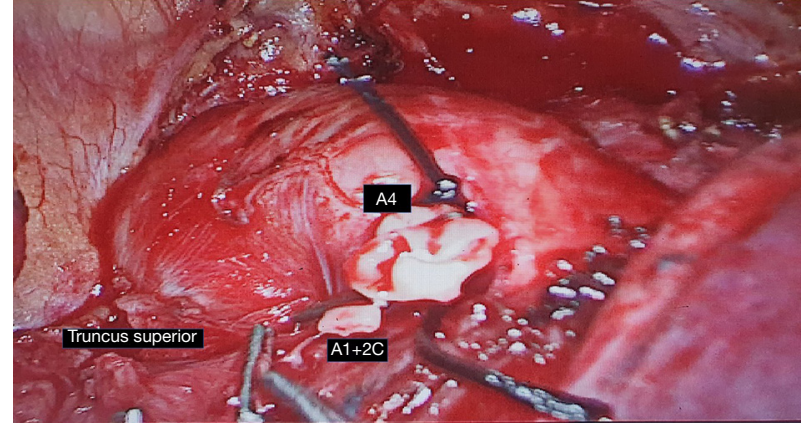

Figure 2 Intraoperative picture of $\mathrm{A} 1+2 \mathrm{c}$ and $\mathrm{A} 4 \mathrm{a}+\mathrm{b}$.

challenges during lobectomy and especially segmentectomy where these structures are embedded deep in the lung parenchyma. Familiarity with these anatomical variations helps avoid intraoperative injury and accidental division (2-5).

Vascular structures of the lung include the pulmonary arteries, pulmonary veins, and bronchial arteries. Segmental pulmonary arteries parallel the bronchi. Unlike the segmental veins which run in the intersegmental plane between two adjacent segmental bronchi, the subsegmental veins run in the intra-segmental and interlobular septa parallel to the segmental and subsegmental pulmonary artery branches and bronchi. Though most common variations are due to venous drainage significant anatomic variations exist in the number and origin of anomalous pulmonary arterial supply to the lobes and segments (2-5).

Anatomic variations on the left lung are more common than on the right $(3,4)$. Pulmonary arterial branches to the left upper lobe can vary from 2 to 7 and are divided into mediastinal, interlobar and segmental/subsegmental types. When the vessel originates from the mediastinal aspect of the left main pulmonary artery it is a mediastinal type. Vessels arising distal to the truncus superior from the truncus intermedius in the fissure is the Interlobar type. Vessels originating within the intralobar lung segment is the segmental/subsegmental types. Truncus superior is the commonest mediastinal type followed by lingula branch $(\mathrm{A} 4+5)$. The lingula arterial supply is solely mediastinal in $18 \%$ and mixed mediastinal and interlobar in $12 \%$. The segmental arterial supply (A8) is solely intralobar and mediastinal origin has not been reported previously (2).

Recognition of this aberrant origin during left VATS upper lobectomy is important as it could be mistaken for mediastinal lingula type and be injured or accidentally ligated. This is especially if the interlobar A4+5 is very small as was in this case. In retrospect what was thought to be

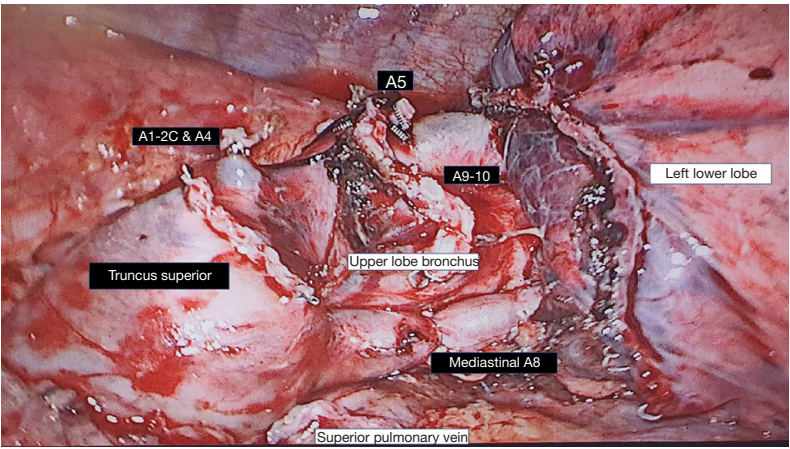

Figure 3 Intraoperative picture after left video assisted thoracoscopic upper lobectomy.

the unusually large A1+2c posterior branch was probably a common trunk origin of A4 lingula branch with an adjacent smaller A1+2c branch (Figures 2,3). Such intraoperative complication can be avoided by detailed preoperative study for possible bronchovascular anatomical variations by simulated 3-dimensional multidetector contrast enhanced computer tomography $(6,7)$. This should be supplemented further by meticulous intraoperative dissection and careful identification of mediastinal and interlobar vessels distally into the respective segments before ligation.

\section{Conclusions}

Though anomalous mediastinal origin of left lower lobe segmental arterial vessels is very rare as compared to lingula vessels it should always be verified intraoperatively as A4+5 or A8 by careful dissection to avoid inadvertent injury or ligation during left VATS upper lobectomy.

\section{Acknowledgments}

Funding: None.

\section{Footnote}

Reporting Checklist: The author has completed the CARE reporting checklist. Available at https://jovs.amegroups. com/article/view/10.21037/jovs-20-139/rc

Peer Review File: Available at https://jovs.amegroups.com/ article/view/10.21037/jovs-20-139/prf

Conflicts of Interest: The author has completed the ICMJE 
uniform disclosure form (available at https://jovs. amegroups.com/article/view/10.21037/jovs-20-139/coif). TA serves as an unpaid editorial board member of fournal of Visualized Surgery from June 2019 to May 2021. The author has no other conflicts of interest to declare.

Ethical Statement: The author is accountable for all aspects of the work in ensuring that questions related to the accuracy or integrity of any part of the work are appropriately investigated and resolved. All procedures performed in this study were in accordance with the ethical standards of the institutional and/or national research committee(s) and with the Helsinki Declaration (as revised in 2013). Written informed consent was obtained from the patient for publication of this case report and accompanying images and videos. A copy of the written consent is available for review by the editorial office of this journal.

Open Access Statement: This is an Open Access article distributed in accordance with the Creative Commons Attribution-NonCommercial-NoDerivs 4.0 International License (CC BY-NC-ND 4.0), which permits the noncommercial replication and distribution of the article with the strict proviso that no changes or edits are made and the original work is properly cited (including links to both the formal publication through the relevant DOI and the license). See: https://creativecommons.org/licenses/by-nc-nd/4.0/.

doi: 10.21037/jovs-20-139

Cite this article as: Agasthian T. Anomalous mediastinal left lower lobe anterior segmental artery (A8) accidentally divided during left VATS upper lobectomy: a case report. J Vis Surg 2023;9:8.

\section{References}

1. Yamada S, Suga A, Inoue Y, et al. Importance of preoperative assessment of pulmonary venous anomaly for safe video-assisted lobectomy. Interact Cardiovasc Thorac Surg 2010;10:851-4.

2. Nomori H, Okada M. Illustrated anatomical segmentectomy for lung cancer. Tokyo: Springer, 2012.

3. Cory RA, Valentine EJ. Varying patterns of the lobar branches of the pulmonary artery. A study of 524 lungs and lobes seen at operation of 426 patients. Thorax 1959;14:267-80.

4. Fréchette E, Deslauriers J. Surgical anatomy of the bronchial tree and pulmonary artery. Semin Thorac Cardiovasc Surg 2006;18:77-84.

5. Warren WH, Milloy FJ. Pulmonary vascular system and pulmonary hilum. Thorac Surg Clin 2007;17:601-17.

6. Oizumi H, Kanauchi N, Kato H, et al. Anatomic thoracoscopic pulmonary segmentectomy under 3-dimensional multidetector computed tomography simulation: a report of 52 consecutive cases. J Thorac Cardiovasc Surg 2011;141:678-82.

7. Fukuhara K, Akashi A, Nakane S, et al. Preoperative assessment of the pulmonary artery by threedimensional computed tomography before videoassisted thoracic surgery lobectomy. Eur J Cardiothorac Surg 2008;34:875-7. 